\title{
Altered leucocyte trafficking and suppressed tumour necrosis factor $\alpha$ release from peripheral blood monocytes after intra-articular glucocorticoid treatment
}

\author{
James H Steer, Dickson T S Ma, Leon Dusci, George Garas, Karen E Pedersen, \\ David A Joyce
}

\begin{abstract}
Objectives-A generalised transient improvement may follow intra-articular administration of glucocorticoids to patients with inflammatory arthropathy. This may represent a systemic anti-inflammatory effect of glucocorticoid released from the joint, mediated through processes such as altered leucocyte trafficking or suppressed release of pro-inflammatory cytokines. Patients, who had received intraarticular injections of glucocorticoids were therefore studied for evidence of these two systemic effects.
\end{abstract}

Methods-Patients with rheumatoid arthritis were studied. Peripheral blood leucocyte counts, tumour necrosis factor $\alpha$ ( TNF $\alpha$ ) release by peripheral blood monocytes, blood cortisol concentrations, and blood methylprednisolone concentration were measured for 96 hours after intraarticular injection of methylprednisolone acetate.

Results-Measurable concentrations of methylprednisolone were present in

Department of Pharmacology, University of Western Australia, Nedlands, Western Australia

$\mathrm{J}$ H Steer

K E Pedersen

D A Joyce

Department of Rheumatology, Sir Charles Gairdner Hospital, Nedlands, Western Australia D T S Ma

G Garas

Department of Clinical Pharmacology and Toxicology, Western Australian Centre for Pathology and Medical Research, Nedlands,

Western Australia

L Dusci

D A Joyce

Correspondence to: Dr D A Joyce, Department of Pharmacology, University of Western Australia, Nedlands, Western Australia, 6907

Accepted for publication 17 September 1998 blood for up to 96 hours after injection. Significant suppression of the hypothalamic-pituitary-adrenal axis persisted throughout this time. Altered monocyte and lymphocyte trafficking, as evidenced by peripheral blood monocytopenia and lymphopenia, was apparent by four hours after injection and resolved in concordance with the elimination of methylprednisolone. Granulocytosis was observed at 24 and 48 hours. Release of TNF $\alpha$ by endotoxin stimulated peripheral blood monocytes was suppressed at four hours and thereafter. Suppression was maximal at eight hours and was largely reversed by the glucocorticoid antagonist, mifepristone. Conclusions-After intra-articular injection of methylprednisolone, blood concentrations of glucocorticoid are sufficient to suppress monocyte $\mathrm{TNF} \alpha$ release for at least four days and to transiently alter leucocyte trafficking. These effects help to explain the transient systemic response to intra-articular glucocorticoids. Suppression of TNF $\alpha$ is principally a direct glucocorticoid effect, rather than a consequence of other methylprednisolone induced changes to blood composition. (Ann Rheum Dis 1998;57:732-737)
Patients with inflammatory arthropathies commonly report transient subjective improvement in polyarticular pain after an intra-articular injection of a depot glucocorticoid. ${ }^{1}$ This occurs as the glucocorticoid is cleared from the joint and circulates in measurable concentrations. $^{2}$

After intra-articular administration of methylprednisolone, the drug concentration and free fraction are sufficient to suppress the hypothalamus-pituitary-adrenal (HPA) axis for several days. ${ }^{2}$ This may be enough for a direct anti-inflammatory action, comparable to the suppression of activity of rheumatoid arthritis by systemic glucocorticoids. Alternatively, the transient systemic response may be consequent on indirect glucocorticoid effects, a placebo effect, an effect of the glucocorticoid on $\operatorname{mood}^{3}$ or simply a result of the period of rest that commonly follows injection of a lower limb joint. Indirect glucocorticoid effects, which are potentially relevant to an indirect antiinflammatory action, include suppression of pro-opiomelanocortin (POMC) gene expression and secretion of corticotrophin releasing hormone $(\mathrm{CRH})$ and somatostatin. These are principally products of neuroendocrine tissue, but inflammatory cells have also been shown to release $\mathrm{CRH}$ and somatostatin and to express the POMC gene, at least in rodents. ${ }^{4-6} \mathrm{CRH}$ secretion and POMC gene expression are glucocorticoid sensitive in neuroendocrine tissue, at least, ${ }^{7}$ while somatostatin release from inflammatory tissue may also be glucocorticoid sensitive. ${ }^{4}$ The POMC gene products ACTH, ${ }^{8}$ $\beta$ endorphin, ${ }^{9}$ and $\alpha$ melanocyte stimulating hormone $\mathrm{e}^{5}$ all modulate aspects of mononuclear leucocyte activity experimentally, as do $\mathrm{CRH}$ and somatostatin. ${ }^{4} 10$

Glucocorticoids act directly on most cells involved in inflammatory or immune responses. ${ }^{11}$ In vivo, lymphopenia and monocytopenia occur during conventional systemic glucocorticoid treatment, varying over a dosage interval according to the glucocorticoid concentration. ${ }^{12}$ In vitro, glucocorticoids suppress release of tumour necrosis factor $\alpha$ ( $\mathrm{TNF} \alpha$ ) and a wide range of other monocyte/ macrophage and lymphocyte activities. ${ }^{11}{ }^{13-16}$ Concentrations achieved in vivo after conventional oral dose are also sufficient to suppress endotoxin stimulated $\mathrm{TNF} \alpha$ release by macrophages. ${ }^{12}$ Glucocorticoids affect cellular adhesion molecule expression on monocytes, lymphocytes, and granulocytes, ${ }^{17-19}$ and modify 
trafficking in normal ${ }^{20}$ and inflamed ${ }^{21}$ tissue. A biphasic change in circulating monocyte numbers, transient lymphopenia, and transient granulocytosis also follow single systemic doses of glucocorticoids. ${ }^{12}{ }^{22}$

In the case of RA, effects of glucocorticoids on leucocyte trafficking and on $\mathrm{TNF} \alpha$ release may be particularly relevant to therapeutic response. Leucocyte recruitment and $\mathrm{TNF} \alpha$ release by cells of the monocyte/macrophage lineage contribute to the pathogenesis of joint inflammation in rheumatoid arthritis. ${ }^{23-25}$

We therefore evaluated peripheral blood leucocyte trafficking and release of $\mathrm{TNF} \alpha$ by peripheral blood monocytes after intraarticular injection of glucocorticoid, seeking evidence for a true anti-inflammatory action outside the injected joint itself.

\section{Methods}

TREATMENT AND SAMPLING PROCEDURE

Six women with rheumatoid arthritis, ${ }^{26}$ aged 42 to 80 years who required intra-articular glucocorticoid treatment to one or more large joints were studied. None had received any systemic or intra-articular glucocorticoid treatment within the six months preceding study. Four patients were taking disease modifying agents and two took non-steroidal anti-inflammatory agents. Between one and five joints were treated simultaneously, between 8 am and 9 am, with depot methylprednisolone acetate injection (Depo-Medrol). Total doses ranged from $40 \mathrm{mg}$ to $240 \mathrm{mg}$ methylprednisolone. Recent studies have reported relatively high incidences of extra-articular placement of corticosteroid during joint injection. ${ }^{27}$ To minimise the incidence of misplaced injections in the study group, recruitment was limited to patients requiring injections of large accessible joints (knee, elbow, and glenohumeral joints). The patients continued in the study if clinical criteria were consistent with correct placement of injections in the target joints. These criteria

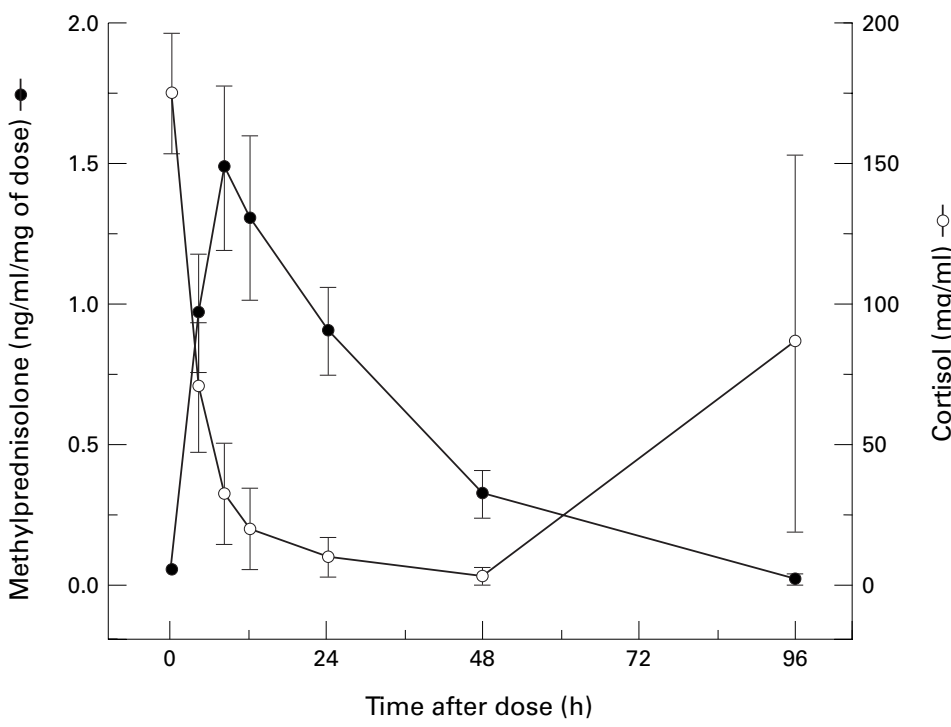

Figure 1 Methylprednisolone and cortisol concentrations in peripheral blood over 96 hours after intra-articular administration of methylprednisolone. At each time point from four hours to 96 hours, the plasma cortisol concentration was significantly lower than the pre-dose value ( $p<0.05$ in each case). included the relation of the needle to bony landmarks, the depth and direction of the needle, facility of access to the target, absence of resistance to flow of injectate and aspiration of fluid (if present). Needle placements were not confirmed by arthrogram because of the possibility that a coadministered contrast agent would modify the pharmacokinetics or pharmacodynamics of the corticosteroid.

Blood samples were collected before dosing and at 4, 8, 12, 24, 48 and 96 hours after completion of injections into EDTA and heparin treated evacuated tubes (Venoject). EDTA anticoagulated blood was used for automated differential white cell counts by a Coulter STKS Analyser ${ }^{28}$ and heparinised blood was used for measurement of plasma cortisol and methylprednisolone by HPLC (see below). Separated heparinised plasma was also tested for capacity to suppress monocyte TNF $\alpha$ production (see below).

Therapeutic concentrations of glucocorticoids transiently reduce the number of monocytes in peripheral blood. ${ }^{12} 29$ This interfered with the interpretation of suppressed $\mathrm{TNF} \alpha$ release from whole blood samples collected after joint injection. To standardise the number of monocytes in each blood sample, a further $35 \mathrm{ml}$ blood sample was collected from each patient two weeks after joint injection. The sample was placed into heparinised tubes, pooled, and then divided into aliquots of 3.5 $\mathrm{ml}$. Each aliquot was centrifuged and $1.3 \mathrm{ml}$ of plasma was removed and replaced with the same volume of plasma from one of the samples collected in the first 48 hours. Each $3.5 \mathrm{ml}$ sample then yielded triplicate samples of $1 \mathrm{ml}$ each in 24 well cell culture plates (Costar). This procedure ensured that equal numbers of autologous monocytes were present with each of the original plasma samples.

Whole blood samples were stimulated with $0.1 \mu \mathrm{g} / \mathrm{ml}$ lipopolysaccharide (LPS) ( $E$ coli, serotype 026-B6; Sigma), added 30 minutes after reconstitution. Additional triplicates were prepared using plasma from the final sample (day 14) and were not stimulated with LPS, to indicate baseline, unstimulated $\mathrm{TNF} \alpha$ production. Similar triplicates were prepared and exposed to LPS, with or without $1 \mu \mathrm{M}$ dexamethasone (Sigma). Dexamethasone was added 30 minutes before LPS. These served to indicate the extent of $\mathrm{TNF} \alpha$ suppression that could be achieved in the individual patient samples with high concentration glucocorticoid exposure. Additional incubates were prepared from the eight hour specimens from each patient and were treated with the glucocorticoid receptor antagonist, mifepristone (RU 486: Roussel-Uclaf) at $50 \mu \mathrm{M}$, to confirm that suppression of TNF $\alpha$ production was because of glucocorticoid present in the sample. Mifepristone was added 30 minutes before LPS. All samples were incubated for four hours at $37^{\circ} \mathrm{C}$ and $5 \%$ carbon dioxide, as previously described. ${ }^{30}$ Plasma was reseparated by centrifugation and $\mathrm{TNF} \alpha$ was measured by sandwich enzyme linked immunosorbent assay, as previously described. ${ }^{31}{ }^{32}$ 
All additives used in the procedure were checked for endotoxin contamination using the Limulus amebocyte lysate test (BioWhittaker Inc, Walkersville, MD) and rejected if endotoxin concentration exceeded $0.1 \mathrm{U} / \mathrm{ml}$. All glassware was baked before use and all plasticware was new.

The studies were approved by the Human Rights Committee of the University of Western Australia and each participant provided written consent.

\section{GLUCOCORTICOID ASSAYS}

Methylprednisolone and cortisol were measured in plasma by high performance liquid chromatography (HPLC), using the same extraction procedures, instrumentation, and conditions as described previously for the assay of prednisolone. ${ }^{12}$ Methylprednisolone (Upjohn) served as standard and dexamethasone
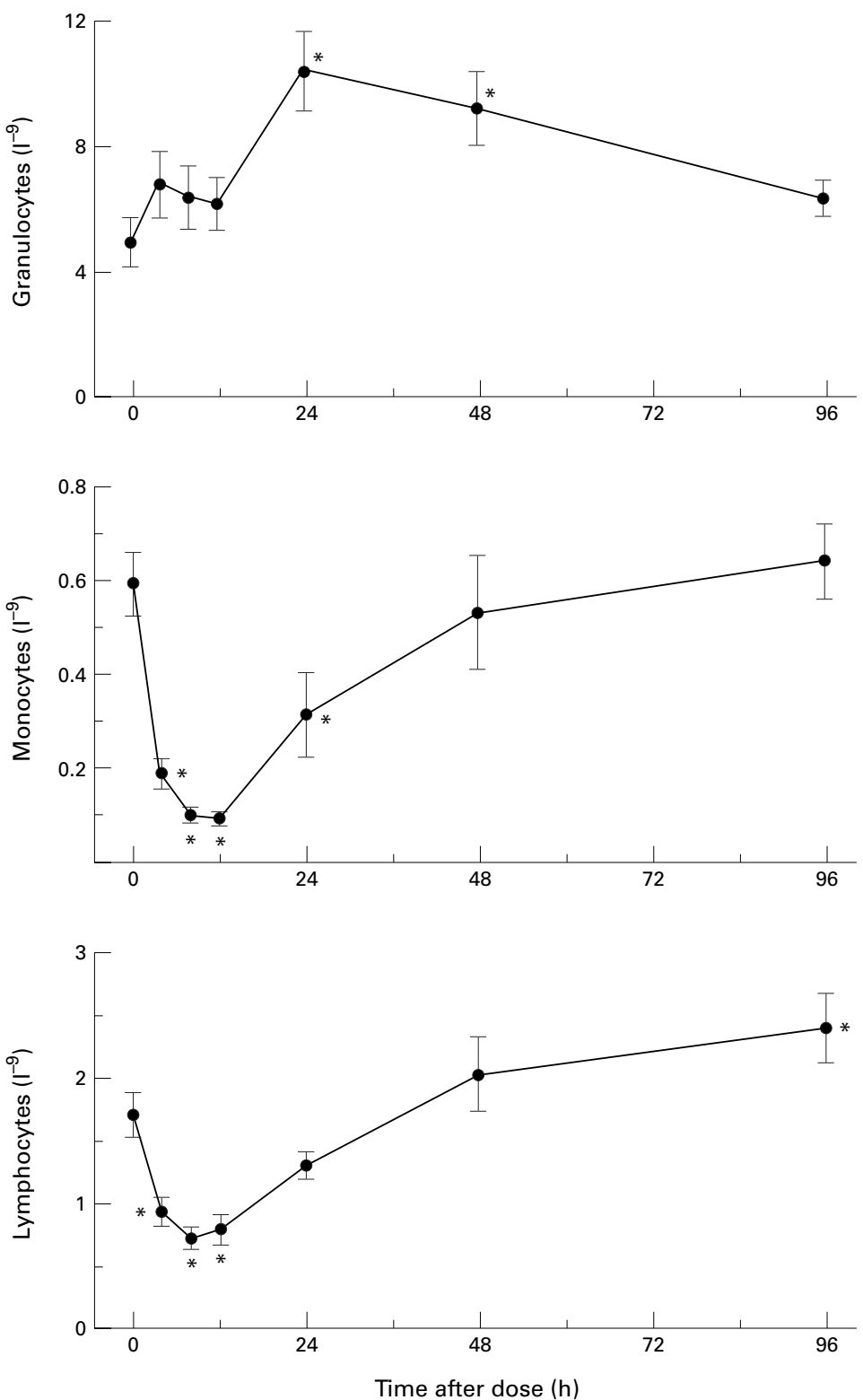

Figure 2 Lymphocyte, monocyte, and granulocyte numbers in peripheral blood over 96 hours after intra-articular administration of methylprednisolone. Significant changes in cell numbers from pre-dose values $(p<0.05)$ are designated by asterisks. The lymphocyte count at 96 hours is significantly higher than the pre-dose value.
(David Bull Laboratories, Melbourne, Australia) was used as an internal standard. Assay sensitivities were $10 \mathrm{ng} / \mathrm{ml}$ for cortisol and methylprednisolone.

DATA ANALYSIS

Statistical analysis was by one way repeated measures ANOVA (SigmaStat, Jandel Scientific). Multiple comparisons against the predose sample (control) for plasma cortisol, plasma methylprednisolone, leucocyte counts, and LPS stimulated $\mathrm{TNF} \alpha$ release were made using the Student-Newman-Keuls test. Data are expressed as mean (SEM). Methylprednisolone concentrations are expressed as ng/ $\mathrm{ml} /$ ( $\mathrm{mg}$ of dose), because absolute doses varied according to patient needs.

\section{Results}

METHYLPREDNISOLONE, CORTISOL, AND LEUCOCYTE KINETICS

Methylprednisolone was detectable in the blood of all patients at four hours after injection. Peak concentrations were measured at eight hours in four patients and 12 hours in two. The patient who received the smallest total dose of methylprednisolone $(40 \mathrm{mg})$ had the lowest peak concentration of $100 \mathrm{ng} / \mathrm{ml}$. The highest peak of $386 \mathrm{ng} / \mathrm{ml}$ occurred in a patient who had received a total of $160 \mathrm{mg}$ of methylprednisolone. The area under the concentration time curve for methylprednisolone, calculated by the trapezoidal rule, increased in relation to the total administered dose $(r=$ $0.80)$.

Measurable concentrations of methylprednisolone were present to 48 hours and one patient still had methylprednisolone detected at 96 hours. The mean cortisol concentration before dosing was $173(21) \mathrm{ng} / \mathrm{ml}$. It had fallen by four hours in all patients. By 24 hours, cortisol was unmeasurable in plasma in four patients (limit of detection: $10 \mathrm{ng} / \mathrm{ml}$ ) and remained unmeasurable to 96 hours in two. Methylprednisolone was still detectable in blood from one of these. She had received 160 $\mathrm{mg}$ of methylprednisolone in total (fig 1).

Mononuclear leucocyte counts and granulocyte counts both responded to intra-articular methylprednisolone, though differently. Significant falls in circulating lymphocyte and monocyte numbers were apparent from the time of the first sample (four hours). Lymphocyte numbers fell to a mean of $42 \%$ of predose concentrations at eight hours, while monocyte numbers fell to a mean of $16 \%$ of pre-dose concentrations at 12 hours (fig 2). Numbers remained significantly suppressed to 24 hours, but had recovered by 48 hours, in each case. This contrasted with persisting suppression of the HPA axis (as evidenced by unmeasurable plasma cortisol concentrations) in four patients at this time. A significant lymphocytosis had developed by 96 hours. Granulocyte leucocyte counts, on the other hand, did not change significantly during the first 12 hours, but increased by 2.1 -fold $(\mathrm{p}<0.05)$ and 1.9 -fold $(\mathrm{p}<0.05)$ at 24 and 48 hours, respectively. By 96 hours, granulocyte counts were not significantly above baseline. 


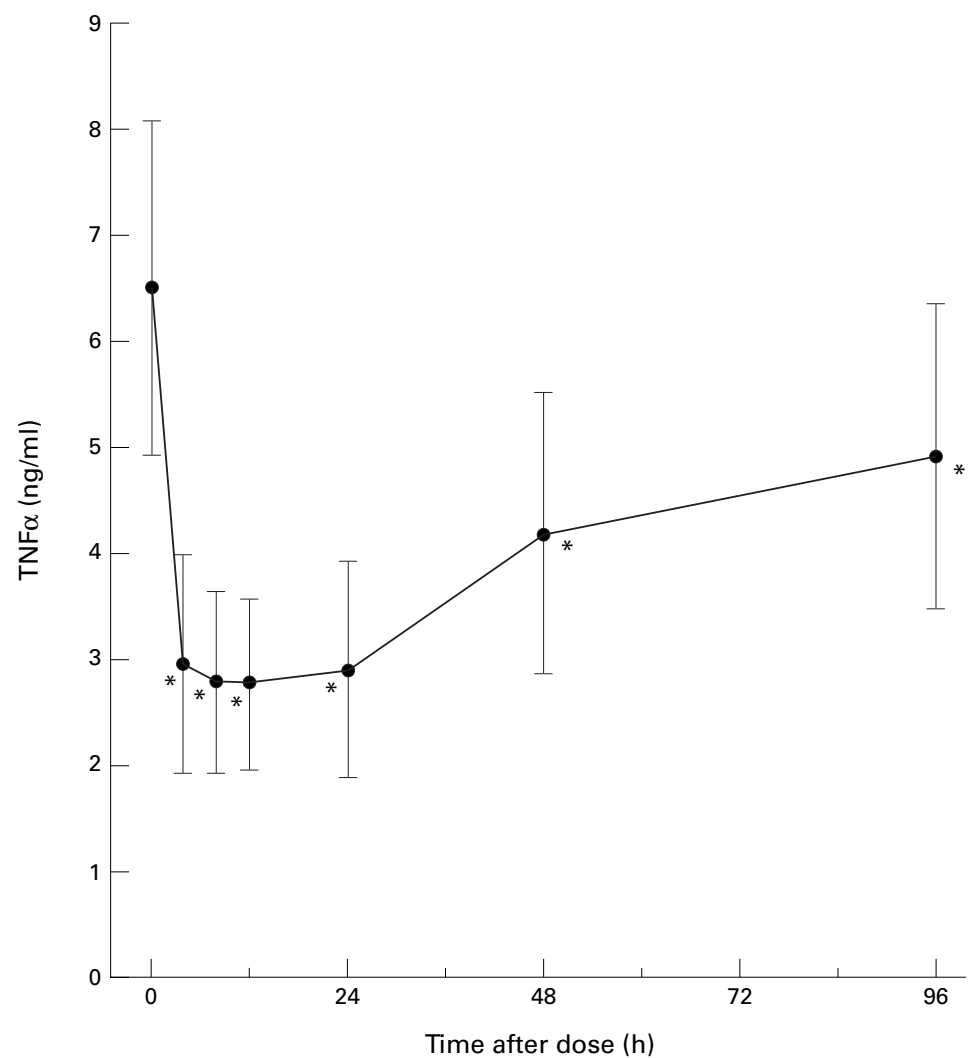

Figure 3 TNFa concentrations (mean (SEM)) in LPS stimulated peripheral blood samples reconstituted with plasma, which was collected before intra-articular injection with methylprednisolone and for 96 hours thereafter. Concentrations of TNFa were significantly lower in all post-dose samples than in the pre-dose samples $\left({ }^{\star} p<0.05\right)$.

EX VIVO RELEASE OF TNF $\alpha$ by whole blood Whole blood samples reconstituted with predose plasma released 6.5 (1.6) $\mathrm{ng} / \mathrm{ml}$ of $\mathrm{TNF} \alpha$ in response to stimulation with LPS for four hours, while unstimulated samples released 0.4 (0.2) $\mathrm{ng} / \mathrm{ml}$. Whole blood samples reconstituted with plasma from subsequent time points, to 96 hours, exhibited lower release of TNF $\alpha$ after LPS stimulation, even though methylprednisolone was detected in only one patient at 96 hours (fig 3).

Maximum suppression of $\mathrm{TNF} \alpha$ release occurred between 4 and 12 hours after injection. LPS stimulated incubates of eight hour samples released $2.8(0.9) \mathrm{ng} / \mathrm{ml}$, which was a mean of $43 \%$ of release from the pre-dose samples. For comparison, the addition of $1 \mu \mathrm{M}$ dexamethasone to the day 14 sample suppressed LPS stimulated $\mathrm{TNF} \alpha$ release to 1.1 (0.3) $\mathrm{ng} / \mathrm{ml}$. This was $18 \%$ of the amount released by the same sample without dexamethasone $(5.6(0.3) \mathrm{ng} / \mathrm{ml})$.

LPS stimulated eight hour samples were treated with $50 \mu \mathrm{M}$ of the glucocorticoid antagonist mifepristone, to confirm that the observed suppression of $\mathrm{TNF} \alpha$ release was a direct consequence of the glucocorticoid present in the sample, rather than a consequence of some other glucocorticoid induced change to plasma composition. Mifepristone restored LPS stimulated release to 5.2 (1.2) $\mathrm{ng} / \mathrm{ml}(\mathrm{p}=0.004$, compared with eight hour sample: Student's $t$ test), which was a mean of $81 \%$ of release from the pre-dose sample $(\mathrm{p}=$

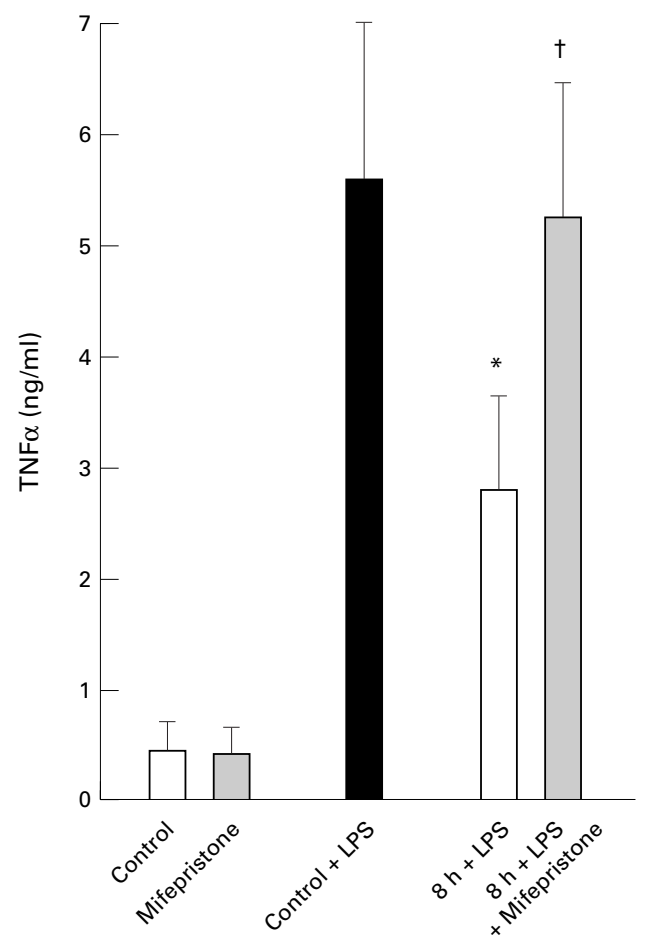

Figure 4 Blood samples taken eight hours after injection release significantly less TNFa upon LPS stimulation (8 hour + LPS) than samples collected 14 days later (control + LPS), when all methylprednisolone had been eliminated ( ${ }^{\star} p=0.01, n=6$, Student's $t$ test). When the

glucocorticoid antagonist, mifepristone $(50 \mu \mathrm{M})$ is added to the eight hour sample, TNFa release increases significantly to concentrations comparable with the control sample $(+p=$ 0.004 , compared with the eight hour sample, without mifepristone; $n=6$, Student's $t$ test). Mifepristone itself does not influence TNFa release from the unstimulated day 14 sample (compare control and mifepristone bars).

NS). Mifepristone $(50 \mu \mathrm{M})$ alone did not lead to release of $\mathrm{TNF} \alpha$ from unstimulated blood samples and nor did it change the LPS stimulated release of $\mathrm{TNF} \alpha$ from the pre-dose sample that contained only endogenous glucocorticoids (fig 4 and results not shown).

\section{Discussion}

Peripheral blood monocytes have impaired ability to release $\mathrm{TNF} \alpha$ for at least four days after the intra-articular injection of 40 to 240 $\mathrm{mg}$ of methylprednisolone acetate. The duration of effect exceeds the time that methylprednisolone can be detected in blood, in most patients, but corresponds with continuing suppression of the HPA axis, as evidenced by low plasma cortisol concentrations. In vitro, concentrations of glucocorticoids sufficient to suppress $\mathrm{TNF} \alpha$ release also suppress release of IL1 $\beta$, IL6, IL8, and a range of other monocyte functions. ${ }^{1415}$

The partial reversal by mifepristone of $\mathrm{TNF} \alpha$ suppression in eight hour specimens confirms that the action of methylprednisolone is mostly direct and not through some glucocorticoid induced modification of other circulating plasma components such as $\mathrm{ACTH},{ }^{8} \beta$ endorphin, ${ }^{9} \alpha \mathrm{MSH},{ }^{5} \mathrm{CRH}$ or somatostatin. ${ }^{40}$ The maximal extent of suppression falls short of that achievable by high concentrations of dexamethasone. The reason for continuing suppression to four days is not 
revealed by these experiments. It may be a continuing direct glucocorticoid effect, because of methylprednisolone present in plasma at concentrations below the sensitivity of the HPLC glucocorticoid assay. This would also explain persistent suppression of the HPA axis. However, non-recovery of the HPA axis at four days does not necessarily mean that plasma methylprednisolone concentrations are still sufficient to suppress monocyte $\mathrm{TNF} \alpha$ release. These data therefore do not exclude an additional indirect action of the glucocorticoid on $\mathrm{TNF} \alpha$ release at later time points.

Systemic doses of glucocorticoids typically cause early, sharp falls in peripheral blood lymphocyte and monocyte numbers, followed by recovery as the glucocorticoid is cleared. Lymphopenia and monocytopenia are relatively brief, compared with suppression of TNFa release and HPA axis function. ${ }^{12}$ The mechanism of disappearance is not fully explained. The findings of this and previous studies ${ }^{33}$ imply that lymphocytes and monocytes leave circulating blood at an accelerated rate. Lymphopenia and recovery are understood to result from redistribution of lymphocytes between blood and other body compartments, particularly the bone marrow. ${ }^{34}{ }^{35}$ The mean transit time of monocytes in the circulation of healthy humans has been estimated as 36 to 104 hours, ${ }^{36}$ so monocytopenia also develops more rapidly than can be explained by cessation of monocyte release from bone marrow alone. The site of redistribution of monocytes has not been defined. The monocytes may not, in fact, leave the blood. It has been estimated that approximately $75 \%$ of monocytes in human blood are marginated and not circulating, ${ }^{37}$ so glucocorticoids may act to change the balance between the circulating and marginated pools in blood. A significant lymphocytosis and a non-significant increase in monocyte numbers occurred at 96 hours, compared with pre-dose values. At this time, most methylprednisolone had been eliminated and endogenous cortisol secretion had yet to re-establish. Similar phenomena occur after an oral glucocorticoid dose $^{12}$ and may be explained either by relative glucocorticoid deficiency at the time, or as a late consequence of the disruption to normal trafficking.

Neutrophilic granulocytosis is also a well recognised effect of glucocorticoid, resulting from increased production in bone marrow and impaired margination. Granulocytosis was delayed, relative to the changes in lymphocyte and monocyte numbers, consistent with increased production. It resolved with elimination of the glucocorticoid.

Glucocorticoids also diminish trafficking of leucocytes to inflamed tissue, contributing to the anti-inflammatory effect. Our experiments did not examine the relation between the antiinflammatory effect and the mechanisms of monocytopenia, lymphopenia or granulocytosis. Recruitment of leucocytes to inflamed tissue involves leucocyte-endothelial cell interactions through surface adhesion molecules. In vivo, glucocorticoids diminish the numbers of leucocyte rolling and adhering to endothelial cells, consistent with reduced granulocyte margination, but neither monocytes nor lymphocytes have been individually examined. ${ }^{38}$ Cell surface adhesion molecules that are directly involved in leucocyte-endothelial cell interaction include ICAM-1, ELAM-1, ${ }^{39}$ E-selectin, ${ }^{40}$ and L-selectin, ${ }^{20}$ which are downregulated by glucocorticoids. These phenomena contribute to the diminished margination of granulocytes, but do not offer a ready explanation for the disappearance of monocytes and lymphocytes from peripheral blood. In the case of monocytes, though, glucocorticoids increase expression of RM3/1, a surface molecule that can contribute to endothelial adhesion. ${ }^{17}$ This may be relevant to glucocorticoid induced monocytopenia.

These experiments show that the low concentrations of glucocorticoid that enter the circulation after intra-articular injection of methyprednisolone acetate are sufficient to temporarily modify leucocyte trafficking and to suppress the release of $\mathrm{TNF} \alpha$ from peripheral blood monocytes for at least four days. These findings support the hypothesis that a direct anti-inflammatory effect of the glucocorticoid, at least, underlies the systemic response that commonly accompanies intra-articular injection.

This work was supported by grants from the National Health and Medical Research Council of Australia and the Arthritis Foundation of Australia. We are grateful to the Department of Haematology, Western Australian Centre for Pathology and Medical Research, for assistance with cell counting.

1 Koehler BE, Urowitz MB, Killinger DW. The systemic effects of intra-articular corticosteroid. J Rheumatol1974;1:117-25.

2 Armstrong RD, English J, Gibson T, Chakraborty J, Marks V. Serum methylprednisolone levels following intraarticular injection of methylprednisolone acetate. Ann Rheum Dis 1981;40:571-4.

3 Swinburn CR, Wakefield JM, Newman SP, Jones PW. Evidence of prednisolone induced mood change ('steroid euphoria') in patients with chronic obstructive airways diseuphoria') in patients with chronic obstructive

4 Karalis K, Mastorakos G, Sano H, Wilder RL, Chrousos GP. Somatostatin may participate in the antiinflammatory GP. Somatostatin may participate in the antiinflammatory actions

5 Star RA, Rajora N, Huang J, Stock RC, Catania A, Lipton JM. Evidence of autocrine modulation of macrophage nitric oxide synthase by alpha-melanocyte-stimulating hormone. Proc Natl Acad Sci USA1995;92:8016-20.

6 van Woudenberg AD, Metzelaar MJ, van der Kleij AA, de Wied D, Burbach JP, Wiegant VM. Analysis of proopiomelanocortin (POMC) messenger ribonucleic acid and POMC-derived peptides in human peripheral blood mononuclear cells: no evidence for a lymphocyte-derived POMC system. Endocrinology 1993;133:1922-33.

7 Nakai Y, Usui T, Tsukada T, Takahashi H, Fukata J, Fukushima M, et al. Molecular mechanisms of glucocorticoid inhibition of human proopiomelanocortin gene transcription. J Steroid Biochem Mol Biol1991;40:301-6.

8 Zwilling BS, Lafuse WP, Brown D, Pearl D. Characterization of ACTH mediated suppression of MHC class II tion of ACTH mediated suppression of MHC class II
expression by murine peritoneal macrophages. J expression by murine peritor

9 Hagi K, Uno K, Inaba K, Muramatsu S. Augmenting effect of opioid peptides on murine macrophage activation. J Neuroimmunol 1994;50:71-6.

10 Schulte HM, Bamberger CM, Elsen H, Herrmann G, Bamberger AM, Barth J. Systemic interleukin-1 $\alpha$ and interleukin-2 secretion in response to acute stress and to corticotropin-releasing hormone in humans. Eur J Clin Invest 1994;24:773-7.

11 Boumpas DT, Chrousos GP, Wilder RL, Cupps TR, Balow JE. Glucocorticoid therapy for immune-mediated diseases: basic and clinical correlates. Ann Intern Med 1993;119: $1198-208$.

12 Steer JH, Vuong Q, Joyce DA. Suppression on human monocyte tumour necrosis factor release by glucocorticoid therapy: relationship to systemic monocytopaenia and cortherapy: relationship to systemic monocytopaenia and cor-

13 Bendrups A, Hilton A, Meager A, Hamilton JA. Reduction

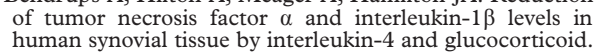
Rheumatol Int 1993;12:217-20. 
14 Amano Y, Lee SW, Allison AC. Inhibition by glucocorticoids of the formation of Interleukin- $1 \alpha$, Interleukin- $1 \beta$ and Interleukin-6: Mediation by decre

15 Standiford TJ, Kunkel SL, Rolfe MW, Evanoff HL, Allen RM, Strieter RM. Regulation of human alveolar macrophage- and blood monocyte-derived interleukin- 8 by prostaglandin E2 and dexamethasone. Am J Respir Cell Mol Biol 1992;6:75-81.

16 Hart PH, Whitty GA, Burgess DR, Croatto M, Hamilton JA. Augmentation of glucocorticoid action on human monocytes by interleukin-4. Lymphokine Res 1990;9:14753.

17 Wenzel I, Roth J, Sorg C. Identification of a novel surface molecule, RM3/1, that contributes to the adhesion of glucocorticoid-induced human monocytes to endothelial cells. Eur J Immunol 1996;26:2758-63.

18 Filep JG, Delalandre A, Payette Y, Foldes-Filep E. Glucocorticoid receptor regulates expression of L-selectin and CD11/CD18 on human neutrophils. Circulation 1997;96:295-301.

19 Pitzalis C, Pipitone N, Bajocchi G, Hall M, Goulding N, Lee A, et al. Corticosteroids inhibit lymphocyte binding to endothelium and intercellular adhesion: an additional mechanism for their anti-inflammatory and immunosuppressive effect. J Immunol 1997;158:5007-16.

20 Sackstein R, Borenstein M. The effects of corticosteroids on lymphocyte recirculation in humans: Analysis of the mechanism of impaired lymphocyte migration to lymph node following methylprednisolone administration. J Invest Med 1995;43:68-77.

21 O'Leary EC, Marder P, Zuckerman SH. Glucocorticoid effects in an endotoxin-induced rat pulmonary inflammation model: differential effects on neutrophil influx, integrin expression, and inflammatory mediators. Am Respir Cell Mol Biol 1996;15:97-106.

22 Derendorf H, Hochhaus G, Mollmann H, Barth J, Krieg $\mathrm{M}$, Tunn S, et al. Receptor-based pharmacokineticpharmacodynamic analysis of corticosteroids. J Clin Pharmacol 1993;33:115-23

23 Arend WP, Dayer J-M. Inhibition of the production and effects of interleukin- 1 and tumor necrosis factor $\alpha$ in rheumatoid arthritis. Arthritis Rheum 1995;38:151-60.

24 Feldmann M, Brennan FM, Elliott M, Katsikis P, Main $\mathrm{RN}$. TNF- $\alpha$ as a therapeutic target in rheumatoid arthritis. Circ Shock 1994;43:179-84

25 Haskard DO. Cell adhesion molecules in rheumatoid arthritis. Curr Opin Rheumatol 1995;7:229-34

26 Arnett FC, Edworthy SM, Bloch DA, McShane DJ, Fries DJ, Cooper NS, et al. The American Rheumatism Association 1987 revised criteria for the classification of rheumatoid arthritis. Arthritis Rheum 1988;31:315-24.

27 Jones A, Regan M, Ledingham J, Pattrick M, Manhire A, Doherty M. Importance of placement of intra-articular steroid injections. BMJ 1993;307:1329-30.
28 Hübl W, Hauptlorenz S, Tlustos L, Jilch R, Fischer M, Bayer PM. Precision and accuracy of monocyte counting: Comparison of two hematology analyzers, the manual differential and flow cytometry. Am J Clin Pathol 1995;103: 167-70.

29 Thompson J, Van Furth R. The effect of glucocorticosteroids on the proliferation and kinetics of promonocytes and monocytes of the bone marrow. J Exp Med 1973;137:10 21.

30 Joyce DA, Steer JH, Beilharz M, Stranger R. A system for assessment of monokine gene expression using human whole blood. Genet. Genetic Analysis: Techniques and Applications 1995;12:39-43.

31 Meager A, Parti S, Leung H, Peil E, Mahon B. Preparation and characterization of monoclonal antibodies directed against antigenic determinants of recombinant human tumour necrosis factor (rTNF). Hybridoma 1987;6:30511.

32 Joyce DA, Steer JH, Kloda A. Dexamethasone antagonises IL-4 and IL-10-induced release of IL-1RA by monocytes but augments IL-4-, IL-10- and TGF- $\beta$-induced suppresion of TNF- $\alpha$ release. J Interferon Cytokine Res 1996;16: 513-19.

33 Thompson J, Van Furth R. The effects of glucocorticosteroids on the kinetics of mononuclear phagocytes. J Exp Med 1970;131:429-42.

34 Fauci AS, Dale DC. The effect of in vivo hydrocortisone on subpopulations of human lymphocytes. J Clin Invest 1974; 53:240-6.

35 Fauci AS, Dale DC. Alternate-day prednisone therapy and human lymphocyte subpopulations. J Clin Invest 1975;55: $22-32$.

36 Beelen RHJ, Bos HJ, Kamperdijk EWA, Hoefsmit EGM. Ultrastructure of monocytes and macrophages. In: Zembala M, Asherson GL, eds. Human monocytes. London: Academic Press, 1989:7-25.

37 Meuret G, Hoffmann G. Monocyte kinetic studies in normal and disease states. Br J Haematol 1973;24:275-85.

38 Farsky SP, Sannomiya P, Garcia-Leme J. Secreted glucocorticoids regulate leukocyte-endothelial interactions in inflammation. A direct vital microscopic study. J Leukocyte Biol 1995;57:379-86.

39 Cronstein BN, Kimmel SC, Levin RI, Martiniuk F, Weissmann G. A mechanism for the antiinflammatory effects of corticosteroids: the glucocorticoid receptor reguates leukocyte adhesion to endothelial cells and expression of endothelial-leukocyte adhesion molecule 1 and intercellular adhesion molecule 1. Proc Natl Acad Sci USA 1992; 89:9991-5.

40 Brostjan C, Anrather J, Csizmadia V, Natarajan G, Winkler $H$. Glucocorticoids inhibit E-selectin expression by targeting NF-kappaB and not ATF/c-Jun. J Immunol 1997;158: 3836-44. 